\title{
Evolución de las poblaciones y del conocimiento de los visones europeo Mustela lutreola (Linnaeus, 1761) y americano Neovison vison (Schreber, 1777) en Bizkaia
}

\author{
Population trends and evolution of the knowledge of European Mustela lutreola \\ (Linnaeus, 1761) and American mink Neovison vison (Schreber, 1777) in Bizkaia
}

\section{Mustela lutreola (Linnaeus, 1761) bisoi europarraren eta Neovison vison (Schreber, 1777) amerikarraren populazioen eta ezagutzaren bilakaera Bizkaian}

\author{
Iñigo Zuberogoitia ${ }^{1, *}$, Juan Manuel Pérez de Ana ${ }^{2}$ \\ ${ }^{1}$ Estudios Medioambientales Icarus. \\ ${ }^{2}$ Servicio de Conservación, red Natura 2000 y Biodiversidad. Diputación Foral de Bizkaia. \\ * Corresponding author: zuberogoitia@icarus.es
}

\section{RESUMEN}

En este artículo se muestra la evolución de las poblaciones y el conocimiento del visón europeo Mustela lutreola (Linnaeus, 1761) y americano Neovison vison (Schreber, 1777) en Bizkaia en las dos últimas décadas (1990-2013). Durante los primeros años de los noventa los visones europeos se distribuían preferentemente por las cuencas orientales, expandiéndose a la práctica totalidad de los ríos al final de la década y retrayéndose a las cuencas del Butrón, Oka y Kadagua, principalmente, en 2010. Mientras tanto, a comienzos de los noventa aparecieron las primeras poblaciones de visón americano en el río Butrón, y poco después en los ríos Artibai y Lea, expandiéndose rápidamente por todas las cuencas de la mitad oriental de Bizkaia. Paulatinamente se desarrollaron trabajos sobre la ecología y comportamiento de ambas especies, destacando aspectos como la selección positiva que ambas especies hacen de la vegetación arbustiva de las riberas, la fuerte territorialidad de los visones europeos o la separación espacial intra-específica en ambas especies. Los estudios mostraron como, en ambas especies, las poblaciones se ordenan de los cauces principales hacia los tributarios, de forma que los machos dominantes mantendrían sus áreas vitales en los principales y entrarían en los secundarios en busca de hembras, mientras que las hembras ocuparían los tributarios y utilizarían tramos de río principal como canales de flujo entre diferentes arroyos de su territorio. Por último, los principales factores que amenazan la supervivencia de las poblaciones de visón europeo son la competencia con el visón americano, la contaminación de las aguas y, de forma notable, la fragmentación del medio como consecuencia de las obras que se realizan en los ríos.

PALABRAS CLAVE: Visón europeo, Visón americano, evolución de las poblaciones, espacies invasoras, programa de erradicación/control.

\begin{abstract}
In this paper we show the population trends and the evolution of the knowledge of European Mustela lutreola (Linnaeus, 1761) and American mink Neovison vison (Schreber, 1777) in Bizkaia during the two last decades (1990-2013). The first European mink occupied the eastern basins, spreading quickly to the rest of the study area but declining again later, the last populations surviving in Butrón, Oka and Kadagua rivers. Concurrently the American mink was detected in the the Butrón river in the first years of the decade of the 90s, and later in Artibai and Lea rivers, rapidly expanding to the rest of the rivers of the middle east of Bizkaia.. We conducted ecological and behavioural studies of both species between 1999 and 2013. Some of the main results showed the preference of both mink species for bramble patches in the river banks, their intra-specific spatial segregation and the strong territoriality of the European mink. In this sense, mink males occupied mainly the main rivers while the home ranges of females were located in secondary streams, using the principal river as corridor between different tributaries. Finally, the main threat factors for the conservation of the European mink population in the area seem to be competition with the American mink, water pollution and river fragmentation due to the construction of new infrastructures.
\end{abstract}

KEY WORDS: European mink, American mink, population trends, invasive species, eradication/control programme.

\section{LABURPENA}

Artikulu honetan, Mustela lutreola (Linnaeus, 1761) bisoi europarrak eta Neovison vison (Schreber, 1777) bisoi amerikarrak azken bi hamarkadotan (1990-2013) Bizkaian izan duten populazioen inguruko bilakaera eta ezagutza azaltzen dira. 90eko hamarkadako lehen urteetan, bisoi europarrak, batez ere, ekialdeko arroetan banatuta zeuden eta, hamarkadaren amaieran, ia ibai guztietara zabaldu ziren. 2010ean, aldiz, batez ere, honako ibaietako arroetara atzera egin zuten: Butroi, Oka eta Kadagua. Bien bitartean, 90eko hamarkadaren hasieran azaldu ziren bisoi amerikarraren lehen populazioak Butroi ibaian, eta handik gutxira Artibai eta Lea ibaietan. Bizkor hedatu ziren Bizkaiko ekialdeko arro guztietan. Pixkanaka, bi espezieen portaerari eta ekologiari buruzko lanak garatu eta honako alderdi hauek nabarmendu zituzten: bi espezieek ibaiertzetako zuhaixka-formako landarediaren inguruan egiten duten hautaketa positiboa, bisoi europarren lurraldetasun handia edo bi espezieen arteko espazio mailako banaketa intra-espezifikoa. Ikerketek agerian utzi zuten bi espezieetan, populazioak ibilgu nagusietatik hasi eta ibaiadarretara banatzen direla; hau da, ar dominanteek beren funtsezko eremuak mantentzen dituzte ibilgu nagusietan eta bigarren mailakoetan emeen bila sartzen dira. Aldiz, emeak ibaiadarretan egoten dira eta ibai nagusiko tarteak beren lurraldeko erreka ugarien arteko fluxubide gisa erabiltzen dituzte. Azkenik, bisoi europarraren populazioen biziraupenerako mehatxu bihurtu diren faktore nagusiak bisoi amerikarrarekin duten lehia, uren kutsadura eta, modu aipagarrian, ibaietan egiten dituzten obren ondorioz gertatzen den ingurunearen haustura izaten dira. 


\section{INTRODUCCIÓN}

La aparición del visón europeo Mustela lutreola (Linnaeus, 1761) en la península lbérica es un enigma que ha suscitado diversos debates y ha generado hipótesis sobre el origen de los primeros individuos (Peltier \& Lodé, 2003; Zabala et al., 2004; Michaux et al., 2005). Lo que no cabe duda es que mientras el visón europeo se expandía por el suroeste del continente, al mismo tiempo iba desapareciendo de la mayor parte de su área de distribución del Centro y Este de Europa (ver Wilson \& Mittermeier, 2009). En cualquier caso, el visón europeo nunca ha llegado a tener buenas poblaciones en el País Vasco y, tan pronto se tuvo información sobre su estatus, se catalogó en la categoría de mayor amenaza (Fernández de Mendiola \& Bea, 1998). El caso del visón americano Neovison vison (Schreber, 1777) es diferente, ya que se conoce con bastante precisión su origen y las fechas del comienzo de su invasión, al menos en el caso de Bizkaia (donde se citó por primera vez en el medio natural en 1993, Zuberogoitia \& Zabala, 2003a), y ha pasado de no existir a ser una especie invasora ampliamente extendida y abundante en apenas dos décadas (Rodríguez-Refojos \& Zuberogoitia, 2011). Una de las principales causas de regresión de las poblaciones de visón europeo se relaciona con la competencia con el visón americano y su rápida expansión por toda el área de distribución de la especie autóctona (Maran et al. 1998; Sidorovich et al. 2010; Podra et al., 2013).

Ambas especies de visones, una por su alto grado de amenaza global y la otra por su carácter invasivo, comenzaron a despertar el interés científico en la península Ibérica en la década de los 80 del siglo pasado (Palazón \& Ruiz-Olmo, 1997; Palazón, 1998; Bravo \& Bueno, 1999), aunque no fue hasta los noventa cuando se publicaron los primeros datos sobre su distribución en Bizkaia (Zuberogoitia et al., 1997; Aihartza et al., 1999; Zuberogoitia et al., 2001). Sin embargo, en una sola década han pasado de ser especies prácticamente desconocidas a ser los vertebrados sobre los que más trabajos científicos se han publicado en nuestra área de estudio. Teniendo en cuenta que se trata de mustélidos semiacuáticos de hábitos discretos, evasivos y difíciles de estudiar, su estudio supone un reto importante que evidencia un creciente interés en el conocimiento de su ecología y comportamiento con el fin último de desarrollar medidas de gestión y conservación adecuadas que aseguren la conservación de la especie autóctona.

En este artículo llevamos a cabo un resumen sobre la evolución poblacional, la ecología y el comportamiento del visón europeo y el visón americano en Bizkaia, obtenido en el transcurso de dos décadas de estudios.

\section{MATERIAL Y MÉTODOS}

El presente artículo es un compendio de los trabajos que se han desarrollado sobre los visones europeo y americano en Bizkaia entre 1990 y 2013. Los datos correspondientes a la década de los noventa fueron obtenidos a partir de transectos en ríos (ver Camacho \& Zuberogoitia, 1998), foqueos nocturnos y registros de atropellos, así como citas de animales muertos por perros, gatos y disparos (Aihartza et al., 1999). Posteriormente, en 1999 comenzamos una serie de proyectos de investigación basados en el trampeo en vivo y el radio-seguimiento de visones europeos en la Reserva de la Biosfera de Urdaibai (11 ejemplares, Rallo et al., 2001), el río Butrón (2 ejemplares) y el río Kadagua (2

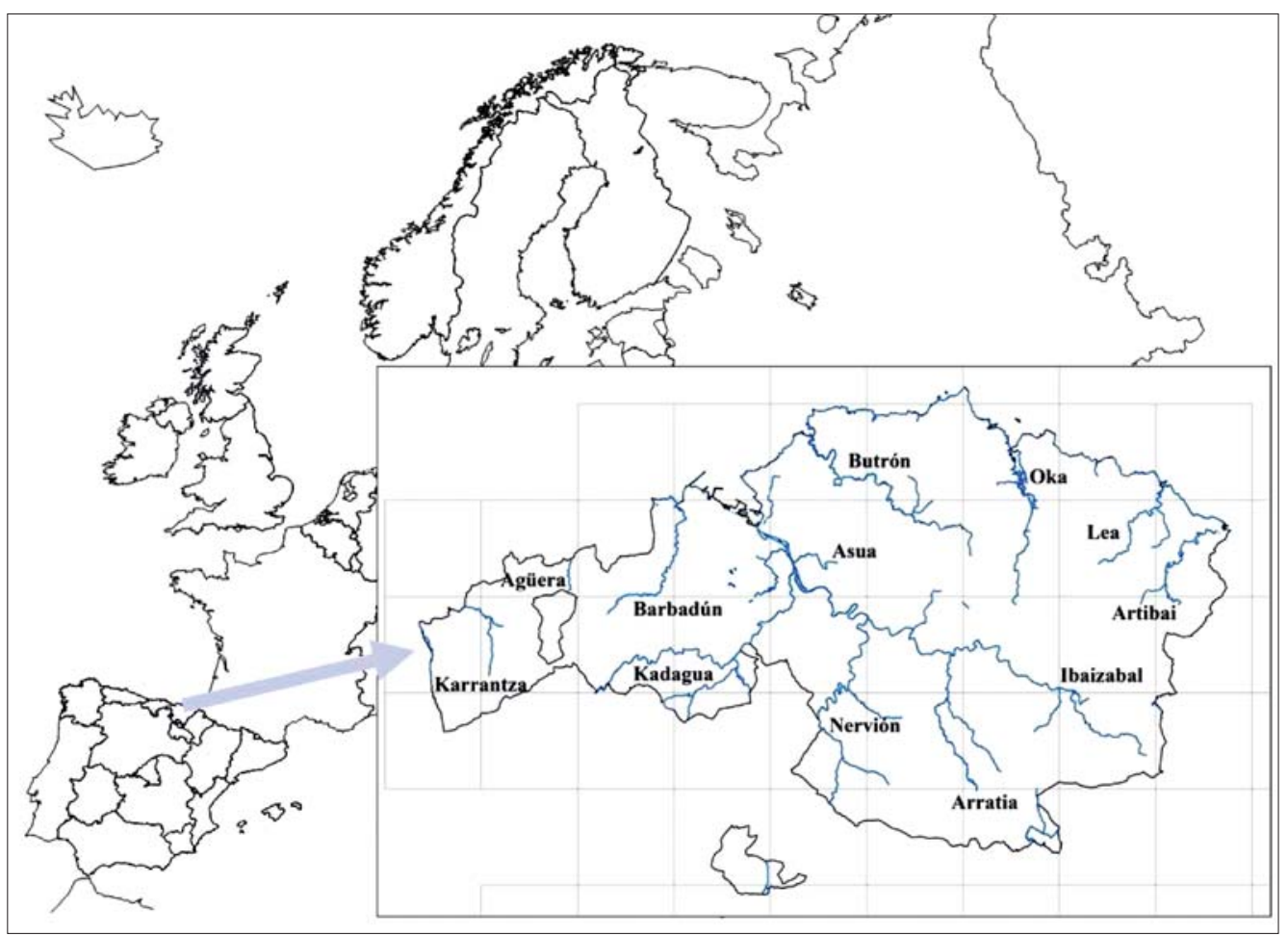

Fig. 1. - Distribución de los principales ríos de Bizkaia Fig. 1. - Distribution of the main rivers of Bizkaia. 
ejemplares) (Zuberogoitia et al., 2005b; 2013; Zabala, 2006; ver Fig. 1 para la ubicación de los cauces); así como 10 visones americanos en el río Butrón (Zuberogoitia et al., 2005b; Zabala, 2006). Por último, en 2007 desarrollamos un protocolo para el control de las poblaciones invasoras de visón americano en la cuenca del río Butrón (Zuberogoitia et al., 2010; Zabala et al., 2010), poniéndolo en práctica en todos los ríos de Bizkaia, salvo el Agüera y el Karrantza (en el límite occidental de distribución de la especie en la provincia), entre 2008 y 2013. Dicho control se basa en un trampeo intensivo en vivo llevado a cabo por los agentes forestales de la Diputación Foral de Bizkaia (ver Zuberogoitia \& Torres, 2013). Asimismo, con las muestras de 78 visones americanos capturados y 18 ejemplares procedentes de la granja peletera de Mutriku, se realizó un análisis genético de microsatélites en 21 loci, para determinar por medio de su similitud genética su procedencia y la capacidad dispersiva de la especie (Zuberogoitia et al., 2013).

\section{EVOLUCIÓN DE LAS POBLACIONES Visón europeo}

La primera cita de visón europeo en la península lbérica fue registrada en Gipuzkoa en 1951 (Rodríguez de Ondarra, 1955). Posteriormente fueron apareciendo nuevas citas que mostraban una tendencia a la expansión de la especie hacia el sur y el oeste (ver Zabala et al., 2004). Las primeras citas en Bizkaia se remontan a 1958 (Rodríguez de Ondarra, 1963) en las localidades de Asua y Abadiano y dos décadas después, en 1985, se citó la especie en tres cuadrículas UTM (10 × 10 km, ver Álvarez et al., 1985, Fig. 2.1). En la década de los noventa se incrementó el número de detecciones como consecuencia de la realización de un trabajo extensivo de distribución de carnívoros en Bizkaia (Aihartza et al., 1999; Zuberogoitia et al., 2001, ver Fig. 2.2), detectando la presencia de la especie en la mayoría de las cuencas del centro y este de Bizkaia y su expansión puntual hacia las cuen-

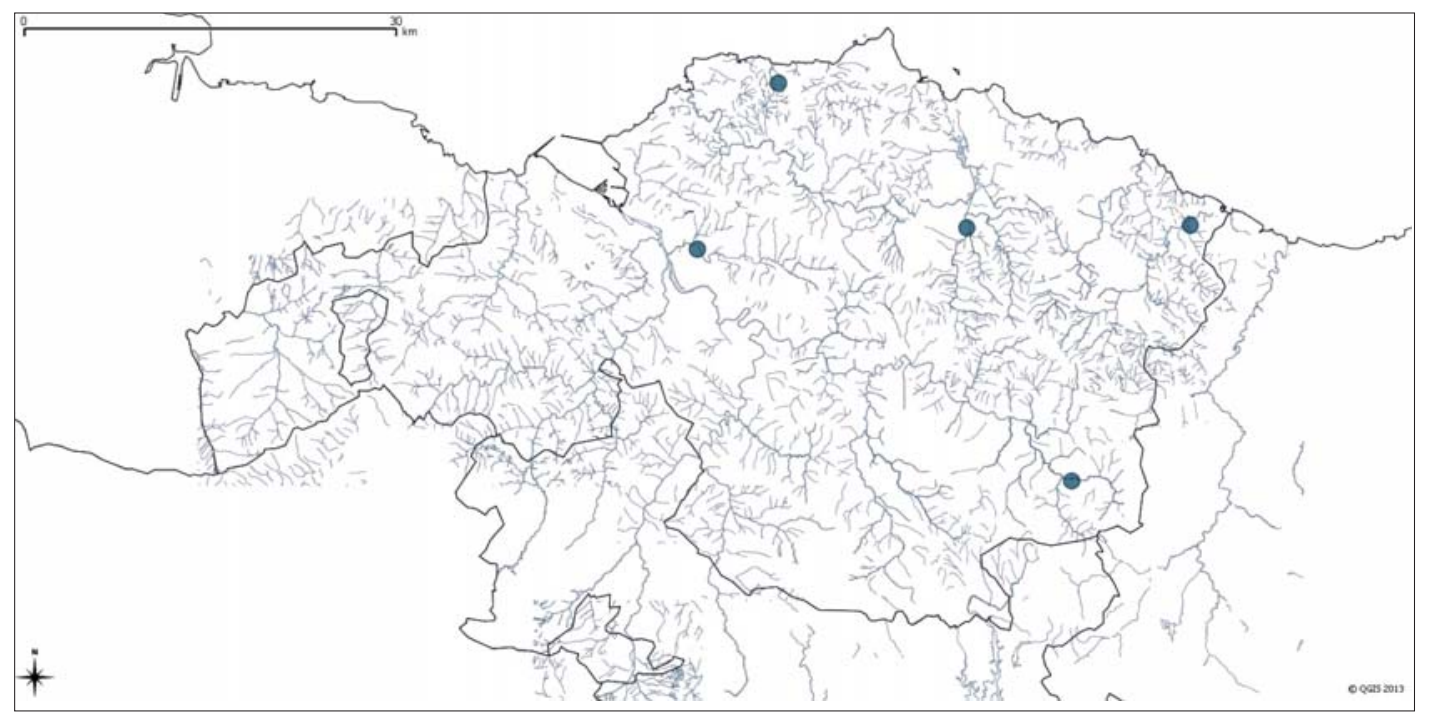

Fig. 2-1. - Localizaciones de visón europeo entre 1957 y 1985 (Álvarez et al., 1985).

Fig. 2-1. - Records of European mink between 1957 and 1985 (Álvarez et al. 1985).

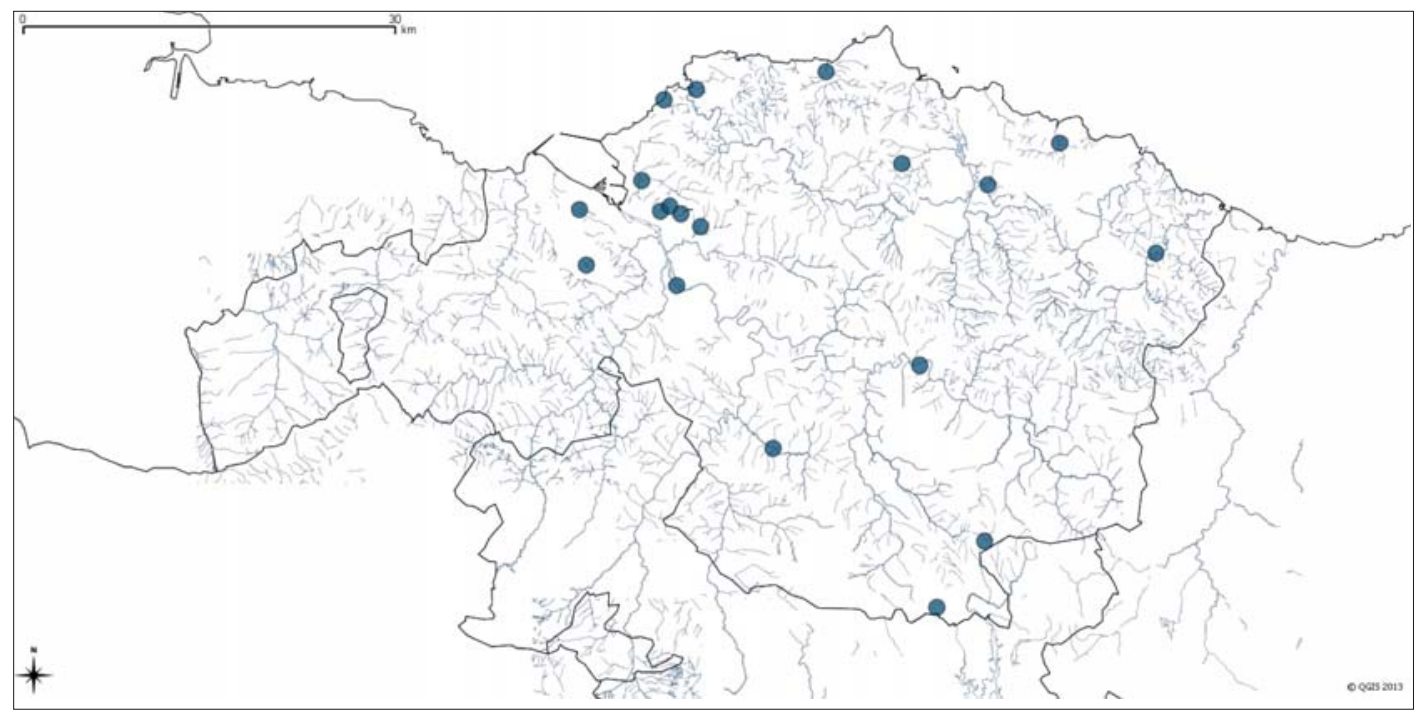

Fig. 2-2. - Localizaciones de visón europeo en la década de los noventa (Aihartza et al., 1999; Zuberogoitia et al., 2001).

Fig. 2-2. - Records of European mink in the 1990s (Aihartza et al., 1999; Zuberogoitia et al., 2001). 
cas occidentales. Entre los años 1999 y 2007 confirmamos la ocupación de la mayoría de los cauces principales, salvo los ríos Mayor y Agüera en el tercio occidental, comprobamos la buena salud de la población de la Reserva de la Biosfera de Urdaibai (Rallo et al., 2001), pero también la existencia de riesgos en las poblaciones de los ríos Butrón, Artibai, Lea e Ibaizabal, en este caso debido a la aparición y rápida expansión del visón americano (Zabala \& Zuberogoitia, 2003c; Zabala et al., 2006a; ver Fig. 2.3., 2.4.) y a las afecciones que estaban sufriendo dichos cauces. Con la información obtenida, se construyó un modelo predictivo que mostraba una tendencia a la reducción poblacional y a la extinción de subpoblaciones en Bizkaia (Zabala \& Zuberogoitia, 2007a). Desgraciadamente, las predicciones de dicho modelo fueron confirmadas con los trabajos llevados a cabo entre 2007 y 2013 (Fig. 2.5. Rodríguez-Refojos \& Zuberogoitia, 2010; Fig. 2.6. Zuberogoitia \& Torres, 2013).
En la actualidad, Bizkaia cuenta con exiguas poblaciones de visón europeo en las cuencas de los ríos Butrón, Urdaibai, Artibai y Kadagua. Estas poblaciones se encuentran sometidas a numerosos factores de amenaza, destacando la competencia con el visón americano, la fragmentación de los ríos y las obras de encauzamiento y canalización de los cauces (Zuberogoitia et al., 2013). Por otro lado, en los últimos años se han detectado algunos ejemplares atropellados en cuencas de los ríos Asua y Artibai, además de un macho joven capturado en el invierno de 2012 en el Artibai, lo cual evidencia la existencia de individuos que resisten en estas cuencas o que acuden desde las poblaciones vecinas con el fin de recolonizarlas de nuevo. Con todo, el panorama actual es el peor de las últimas décadas y, si bien en los últimos años se ha avanzado en el control del visón americano, aún queda mucho por hacer para evitar la fragmentación de los ríos y el deterioro de las cuencas,
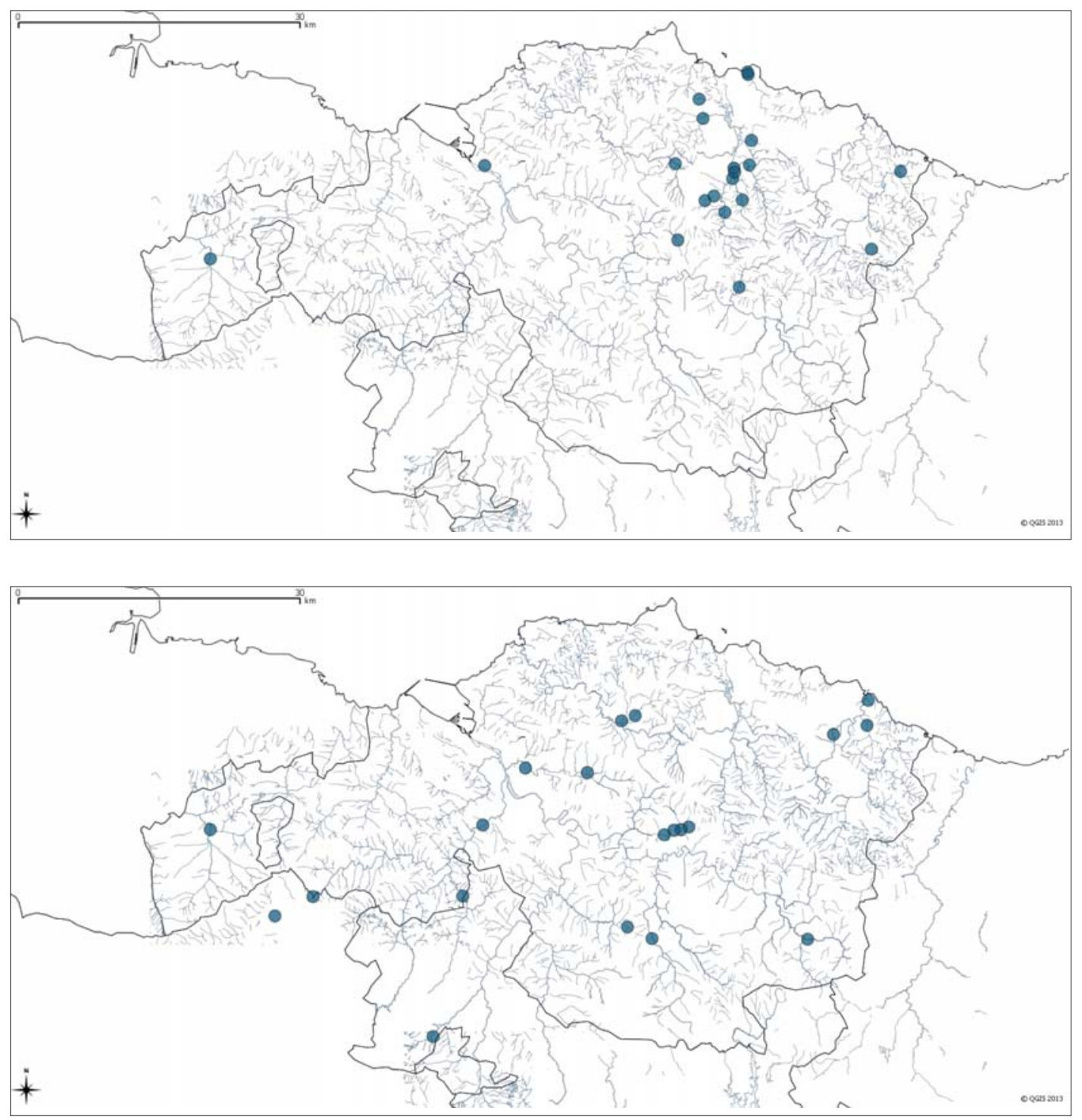

Fig. 2-3. - Capturas de visón europeo en la Reserva de la Biosfera de Urdaibai (Rallo et al., 2001) y el registro de nuevos datos de observaciones directas y atropellos en Bizkaia entre 2000 y 2004.

Fig. 2-3. - Records of trapped of European mink in Urdaibai Biosphere Reserve (Rallo et al., 2001) and sights and road casualties in Bizkaia between 2000 and 2004.

Fig. 2-4. - Capturas de visón europeo entre 2004 y 2007 como resultado de un muestreo específico en todas las cuencas de Bizkaia a excepción de la Reserva de la Biosfera de Urdaibai (Zuberogoitia et al., 2005).

Fig. 2-4. - Records of trapped European mink during a specific study in all rivers of Bizkaia but Urdaibai Biosphere Reserve between 2004 and 2007. 


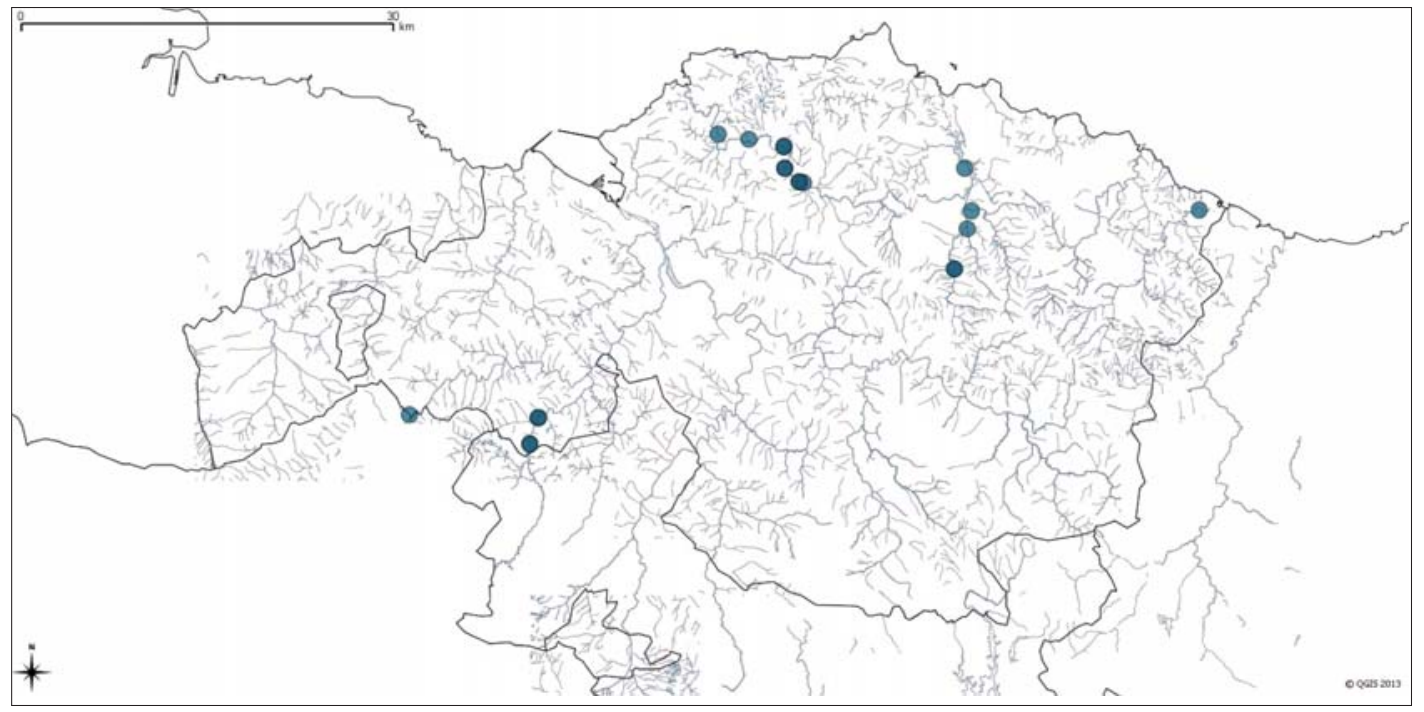

Fig. 2-5. - Localizaciones de visón europeo entre 2007 y 2010 como resultado de tres campañas de muestreo (Zuberogoitia et al., 2012) y el registro de nuevos datos de atropellos. Fig. 2-5. - Records of trapped European mink and road casualties during tree trapping periods between 2007 and 2010 (Zuberogoitia et al., 2012).

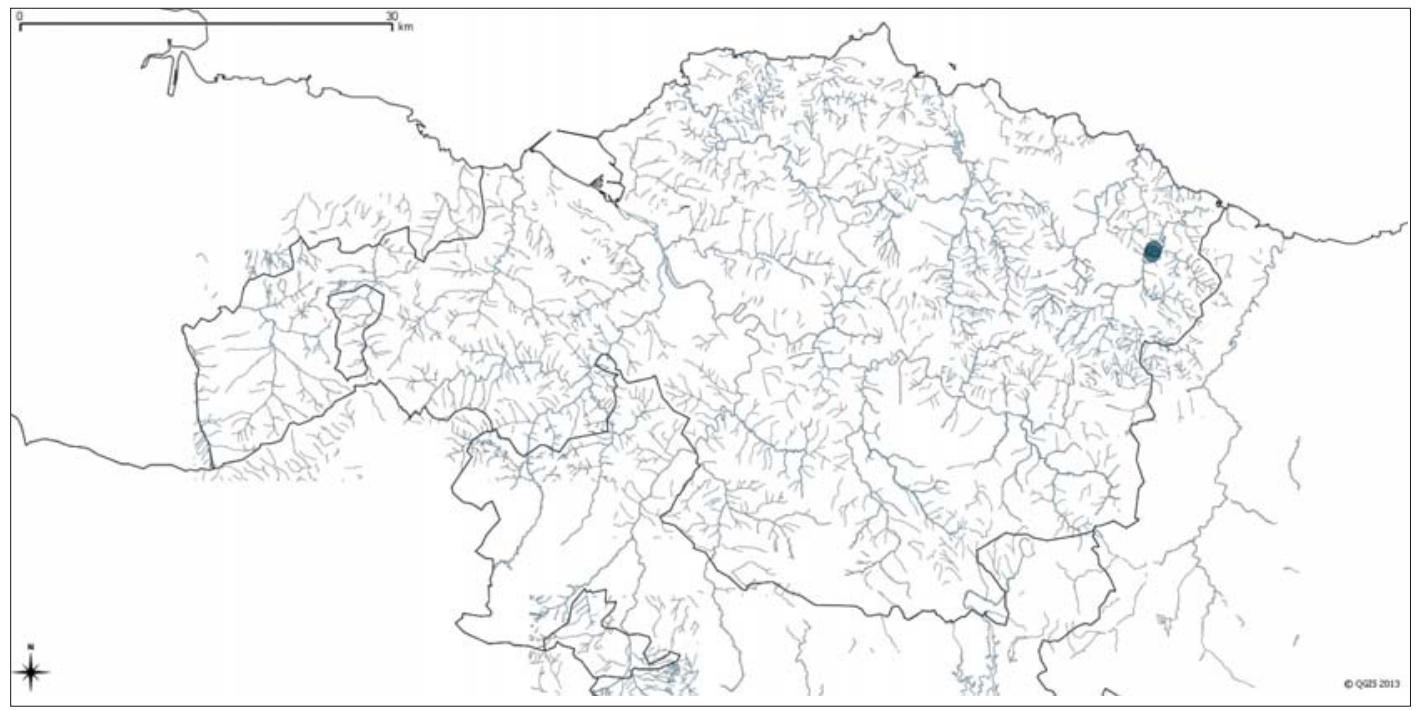

Fig. 2-6. - Capturas de visón europeo entre 2011 y 2013 (Zuberogoitia \& Torres, 2012, 2013).

Fig. 2-6. - Records of trapped European mink between 2011 and 2013 (Zuberogoitia \& Torres, 2012, 2013).

responsables junto con la especie invasora de la situación crítica de la especie en Bizkaia.

\section{Visón americano}

En las décadas de los setenta y ochenta se establecieron varias granjas de visones americanos en Bizkaia. Algunas de estas granjas sufrieron actos vandálicos que provocaron el escape de un gran número de ejemplares, mientras que en otras se produjeron escapes ocasionales como consecuencia del manejo y las carencias de aislamiento en las instalaciones. Además, muchos individuos fueron liberados en el medio natural tras la quiebra de las granjas. En la Fig. 3 se muestra la ubicación de las granjas más importantes que sirvieron de fuente de individuos al medio natural (Zuberogoitia \& Zabala, 2003a). Pese a que muchos de los escapes se produjeron en los años ochenta y que las observaciones de "nutrias" en los ríos se fueron haciendo cada vez más frecuentes, no fue hasta
1993 cuando se capturó el primer visón americano establecido en el medio natural, en el río Butrón (ver Zuberogoitia et al., 1997). Durante los siguientes años continuaron apareciendo citas de la especie invasora en el río Butrón, a las que se sumaron citas puntuales en los ríos Oka (Zugastieta), Asua y Nervión (Arrigorriaga) (ver Fig. 4.1.). Estos primeros datos mostraban la presencia de una población establecida en la cuenca del río Butrón y el comienzo de la dispersión de ejemplares al cercano río Oka (Reserva de la Biosfera de Urdaibai), así como la presencia de ejemplares en otros ríos de Bizkaia.

Entre los años 2000 y 2004 la especie se detectó también en los ríos Artibai, Lea e Ibaizabal (Fig. 4.2.) y aunque se realizó un trampeo intensivo en la Reserva de la Biosfera de Urdaibai, no se capturó ningún ejemplar (ver Rallo et al., 2001). Estos datos sugerían la entrada de nuevos individuos desde el este (probablemente desde las granjas cercanas de Gipuzkoa, por el río Artibai) y la rápida expansión de la especie hacia las cuencas vecinas. 


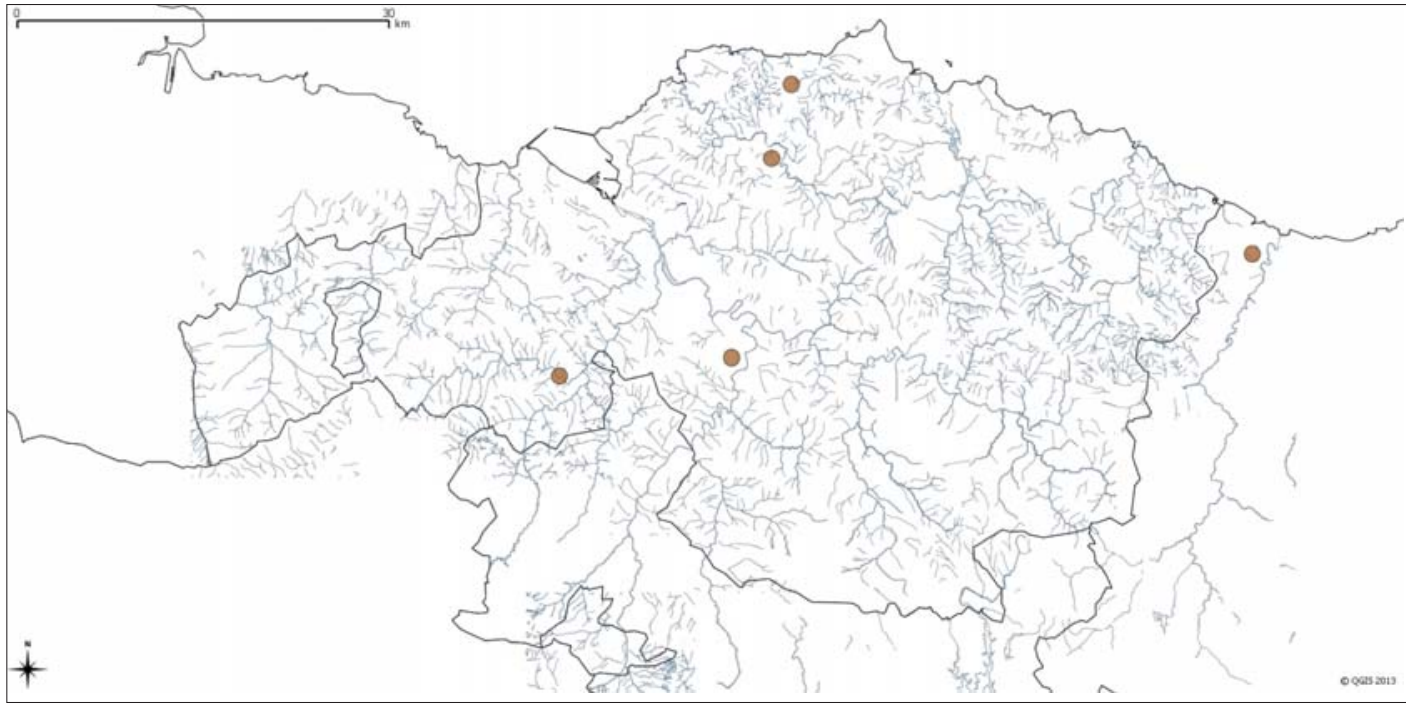

Fig. 3. - Localización de las granjas de visón americano donde se sabe que se han producido escapes masivos.

Fig. 3. - American mink ranch in which escaped were reported.

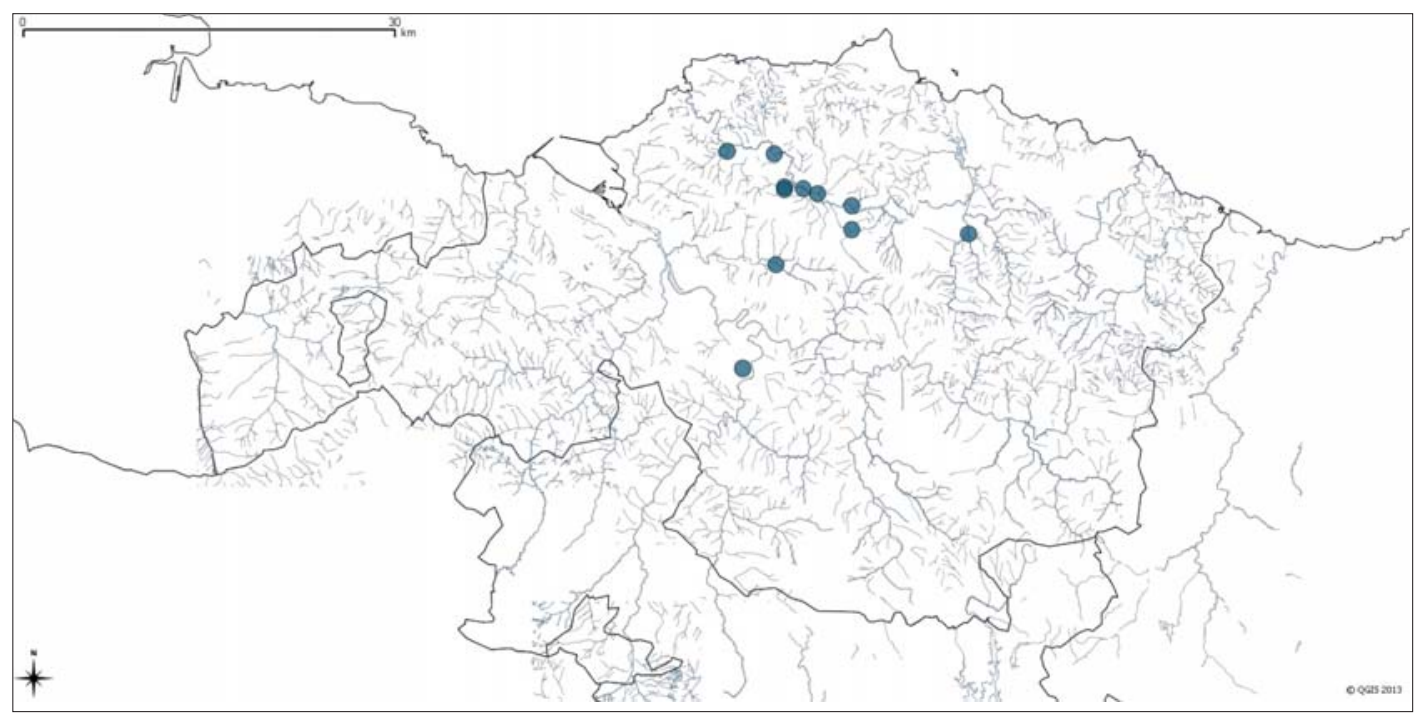

Fig. 4-1. - Citas de visón americano en el periodo 1993-1999 (Aihartza et al., 2001). Fig. 4-1. - Records of American mink between 1993 and 1999 (Aihartza et al., 2001).

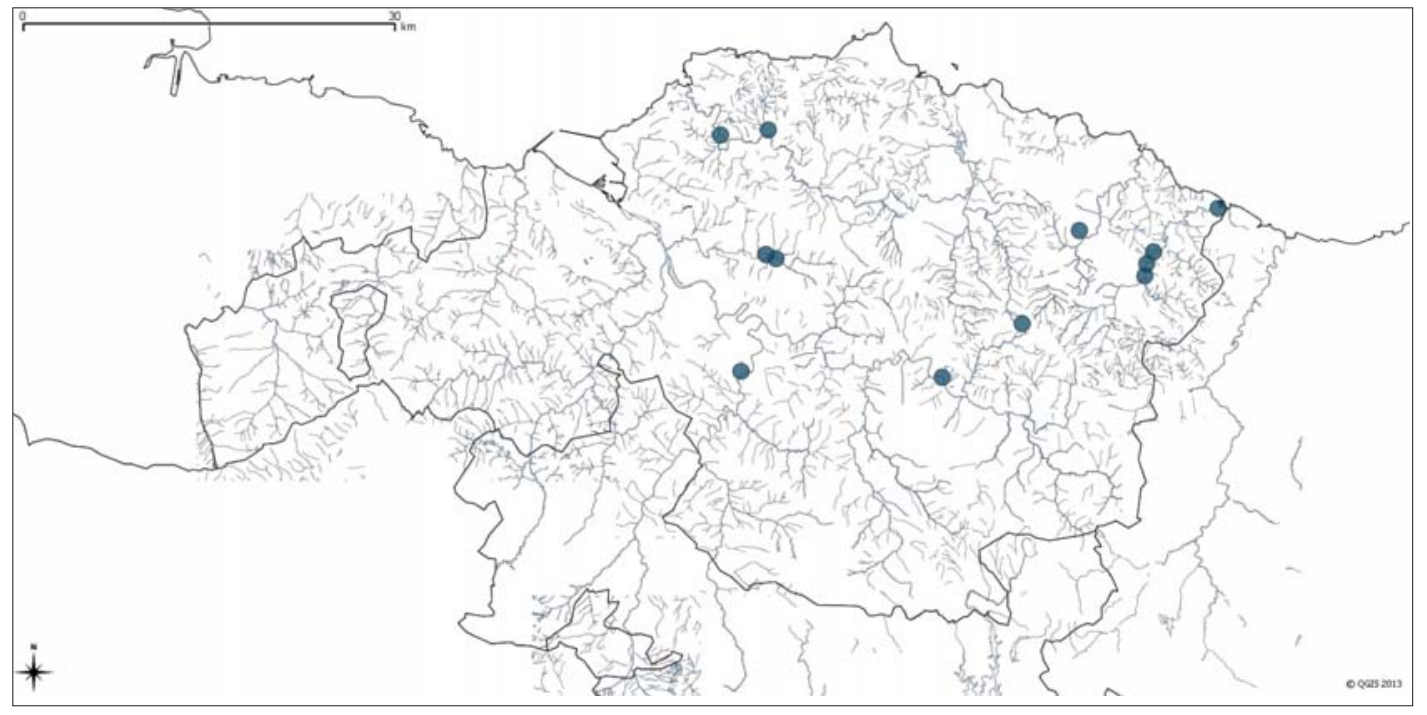

Fig. 4-2. - Citas de visón americano en el periodo 20002004 (Zuberogoitia \& Zabala, 2003a).

Fig. 4-2. - Records of American mink between 2000 and 2004 (Zuberogoitia \& Zabala, 2003a). 
Durante la temporada 2004-2005 se realizó un trampeo extensivo en todos los cauces de Bizkaia a excepción de la Reserva de la Biosfera de Urdaibai, capturando ejemplares en los ríos Artibai, Lea y Butrón. También se recopilaron datos de atropellos y observaciones directas de individuos en las cuencas de los ríos Oka, Ibaizabal, Asua, Bolue y Nervión (ver Zabala, 2006; Fig. 4.3.). Los datos mostraban la invasión del río Oka y la expansión hacia otras cuencas del sur y oeste. En el otoño-invierno de 2007 desarrollamos un protocolo de trampeo en la cuenca del río Butrón con el objetivo de controlar/erradicar a esta especie invasora (ver Zuberogoitia et al., 2010), ampliándolo al resto de las cuencas con presencia confirmada y sospechas de la existencia de individuos entre 2008 y 2013 (Zuberogoitia \& Torres, 2013). Durante esos seis años se capturaron 163 ejemplares distribuidos en los ríos Artibai, Lea, Oka, Butrón), Ibaizabal y Asua (Tabla 1). También localizamos ejemplares atropellados y recogimos observaciones directas en otros puntos hasta completar el mapa de distribución mostrado en las figuras 4.4. y 4.5.

Cuando desarrollamos los modelos de expansión del visón americano en Bizkaia (Zabala \& Zuberogoitia, 2007) se obtuvo una predicción de la evolución de la población hasta la situación actual, pero no sospechábamos que pudiera ser tan rápida.

Los análisis genéticos revelaron que la población vizcaína procede, en su mayor parte, del escape producido en Mungia, río Butrón, a finales de los ochenta (Zuberogoitia et al., 2013). Durante los primeros años la población fue prosperando en este cauce hasta que, una vez alcanzada la saturación de la cuenca, se comenzó un rápido proceso dispersivo hacia el este y el sur. Mientras tanto, se confirmaba la presencia de visones americanos en el río Artibai y Lea con el genotipo de la granja de Mutriku que se encontraron y mezclaron con la población en expansión procedente del Butrón (Zuberogoitia et al., 2013).

Sin embargo, pese a los sucesivos intentos por colonizar los ríos Ibaizabal, Nervión y cauces menores, aún no se han detectado poblaciones establecidas en esas zonas, sino citas puntuales y esporádicas. Este hecho podría estar asociado a la baja capacidad de carga de estos ríos debido al mal estado de sus cauces (Zabala et al., 2006a; Zabala, 2006) y al alto nivel de fragmentación de los ríos, con un gran número de barreras que impiden el flujo entre los tributarios y el cauce principal y, por lo tanto, reducen la capacidad de carga del río para acoger poblaciones estables de visones (Zuberogoitia et al., 2013).

\section{ÁREAS DE CAMPEO}

Los resultados de las investigaciones realizadas en Bizkaia muestran como ambas especies presentan una gran territorialidad intrasexual, más marcada en el caso del visón europeo (Zabala \& Zuberogoitia, 2003d). Las áreas de campeo de los visones europeos machos se extendieron a lo largo de 13,13 km de cauce ( $D E=2,84$; rango 11,1 - 17,5; $\mathrm{n}=7$ ), mientras que las de los americanos seguidos eran de 7,05 km (DE = 7,78; rango 1,2-15,9; $\mathrm{n}=3$ ), tanto de cauces principales como tributarios, pequeños

\begin{tabular}{|c|c|c|c|c|}
\hline Periodo & Cauces & $\begin{array}{l}\text { Esfuerzo } \\
\text { (TN) }\end{array}$ & $\begin{array}{l}\text { No. visones } \\
\text { americanos }\end{array}$ & $\begin{array}{c}\text { Indice de } \\
\text { captura }\end{array}$ \\
\hline $2007-2008$ & Butron & 2242 & 31 & 72,3 \\
\hline \multirow[t]{5}{*}{ 2008-2009 } & Butron & 1067 & 12 & 88,9 \\
\hline & Lea-Artibai & 1109 & 14 & 79,2 \\
\hline & Urdaibai & 1233 & 13 & 94,8 \\
\hline & Ibaizabal & 758 & 2 & 379 \\
\hline & Arratia-Nervion & 928 & 0 & \\
\hline \multirow[t]{9}{*}{2010} & Butron & 737 & 10 & 73,7 \\
\hline & Lea-Artibai & 836 & 5 & 167,2 \\
\hline & Urdaibai & 742 & 7 & 106,0 \\
\hline & Ibaizabal & 640 & 0 & \\
\hline & Arratia-Nervion & 780 & 0 & \\
\hline & Kadagua & 894 & 0 & \\
\hline & Barbadún & 690 & 0 & \\
\hline & Asua & 160 & 1 & 160,0 \\
\hline & Deba & 96 & 0 & \\
\hline \multirow[t]{6}{*}{2011} & Butron & 935 & 4 & 234,0 \\
\hline & Lea-Artibai & 940 & 8 & 118,0 \\
\hline & Urdaibai & 1296 & 7 & 185,0 \\
\hline & Ibaizabal & 160 & 0 & \\
\hline & Asua & 96 & 1 & 96,0 \\
\hline & Urkiola & 160 & 0 & \\
\hline \multirow[t]{5}{*}{2012} & Butron & 1226 & 7 & 175,1 \\
\hline & Lea-Artibai & 654 & 2 & 327,0 \\
\hline & Urdaibai & 1248 & 11 & 113,5 \\
\hline & Ibaizabal & 160 & 0 & \\
\hline & Asua & 140 & 0 & \\
\hline \multirow[t]{6}{*}{2013} & Butron & 952 & 9 & 105,8 \\
\hline & Lea-Artibai & 1037 & 13 & 79,8 \\
\hline & Urdaibai & 1240 & 6 & 206,7 \\
\hline & Ibaizabal & 160 & 0 & \\
\hline & Asua & 112 & 0 & \\
\hline & Nervión & 835 & 0 & \\
\hline TOTAL & & 24263 & 163 & 148,9 \\
\hline
\end{tabular}

Tabla 1. - Esfuerzo de trampeo, medido por el número de trampas noche (TN) que estuvieron activas las trampas en cada cuenca en los seis periodos de trampeo (2007-2013), número de visones americanos capturados e índice de captura relativo a las trampas noche necesarias para capturar un visón americano.

Table 1. Sampling effort. Number of trap nights (TN) in each river basin in the six sampled periods (2007-2013), number of mink caught and trapping ratio related to the number of TN needed for trap one mink.

regatos y canales de desagüe (Garin et al., 2002b; Zabala \& Zuberogoitia, 2003c; Zuberogoitia et al., 2005, 2013; Zabala 2006; Zabala et al., 2006a, 2007a,c). En el interior de un área de campeo de un macho se suele encontrar el de varias hembras, con un área de campeo de $3,40 \mathrm{~km}$ de media ( $D E=2,76$; rango $0,6-6,0 ; n=3$ ) en el caso de las europeas y de 4,92 km (DE = 3,79; rango 2,1-10,5; $\mathrm{n}=$ 4) en el de las americanas.

Las hembras de ambas especies suelen preferir tributarios y pequeños arroyos, aunque también cauces principales como conexión entre tributarios, existiendo una competencia intra-específica que determina la segregación espacial entre y dentro de los sexos (Zabala et al., 2007b). Considerando las capturas de visones americanos del programa de control de la especie entre 2007 y 2013, se observa una segregación espacial por 


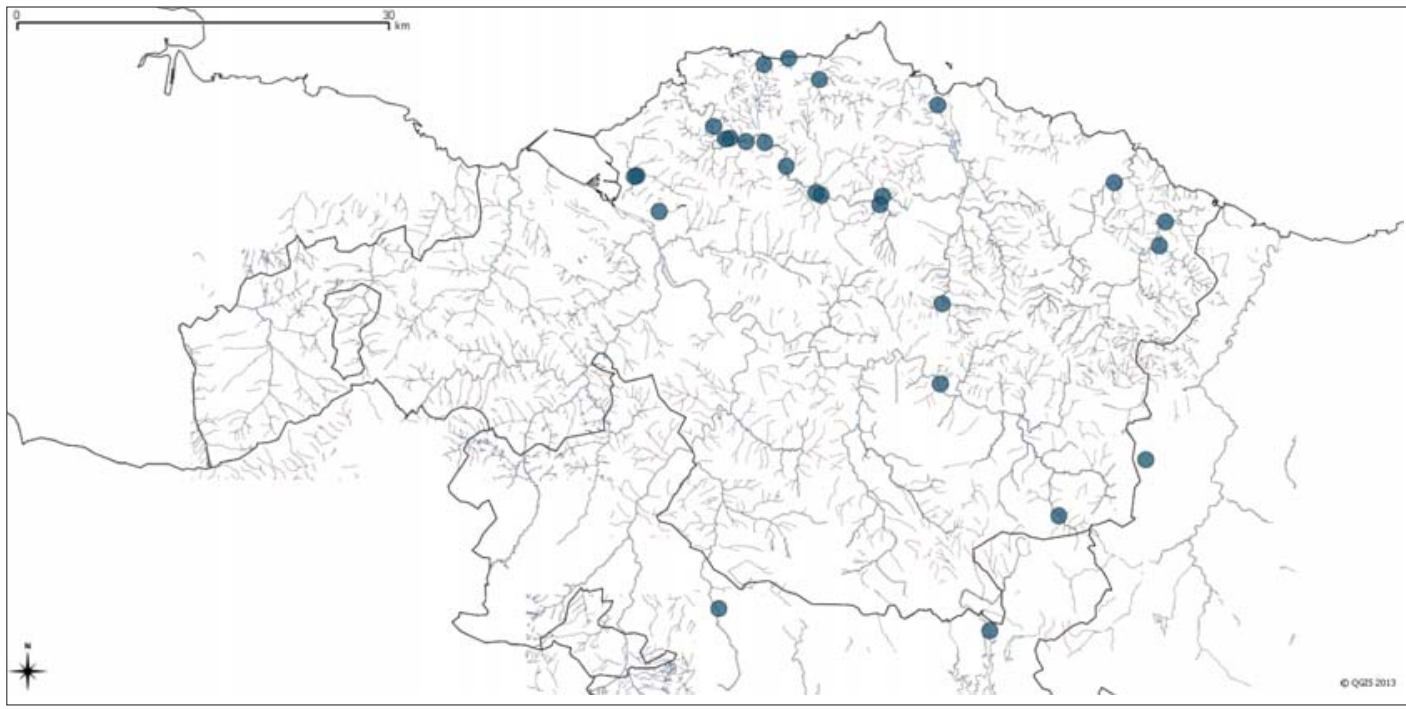

Fig. 4-3. - Capturas de visones americanos en el periodo 2004-2007 (Zabala, 2006).

Fig. 4-3. - Records of trapped American mink between 2004 and 2007 (Zabala, 2006).

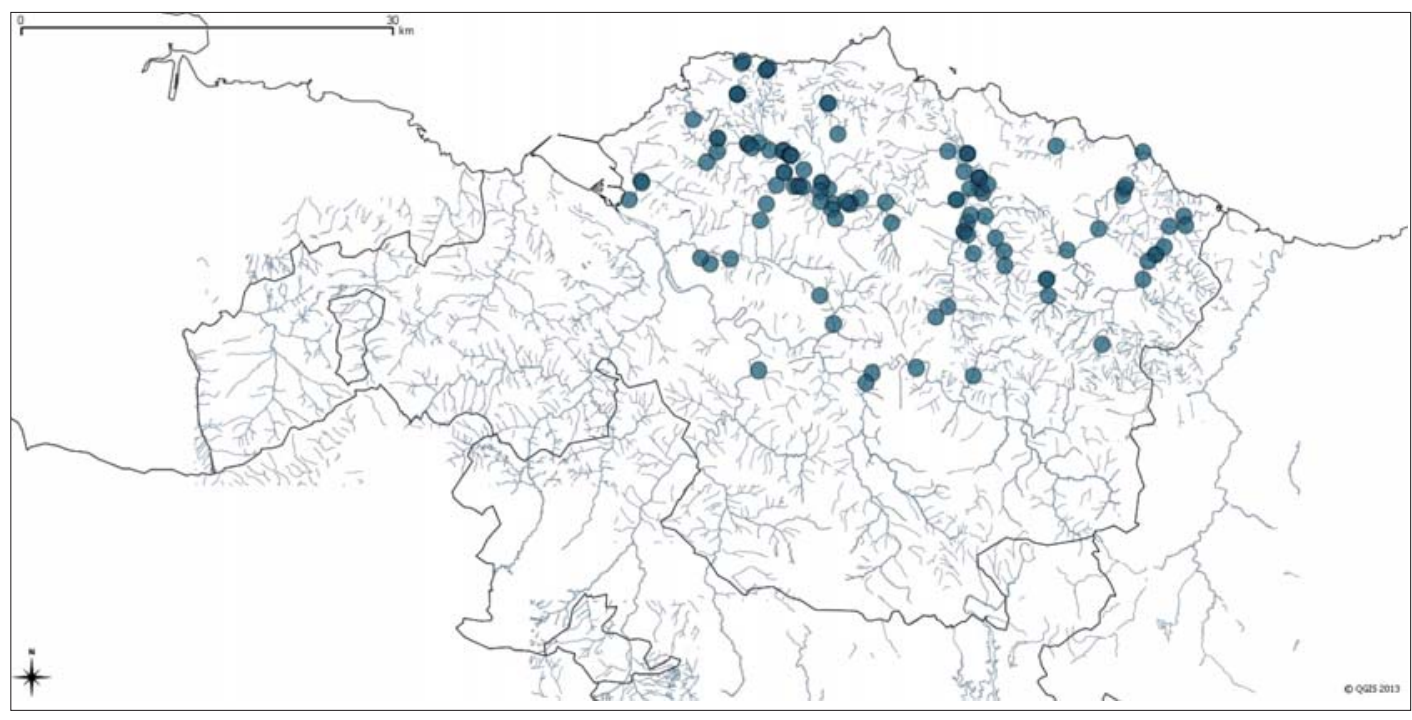

Fig. 4-4. - Capturas de visones americanos en el periodo 2007-2010.

Fig. 4-4. - Records of trapped American mink between 2007 and 2010 (Rodríguez-Refojos \& Zuberogoitia, 2011).

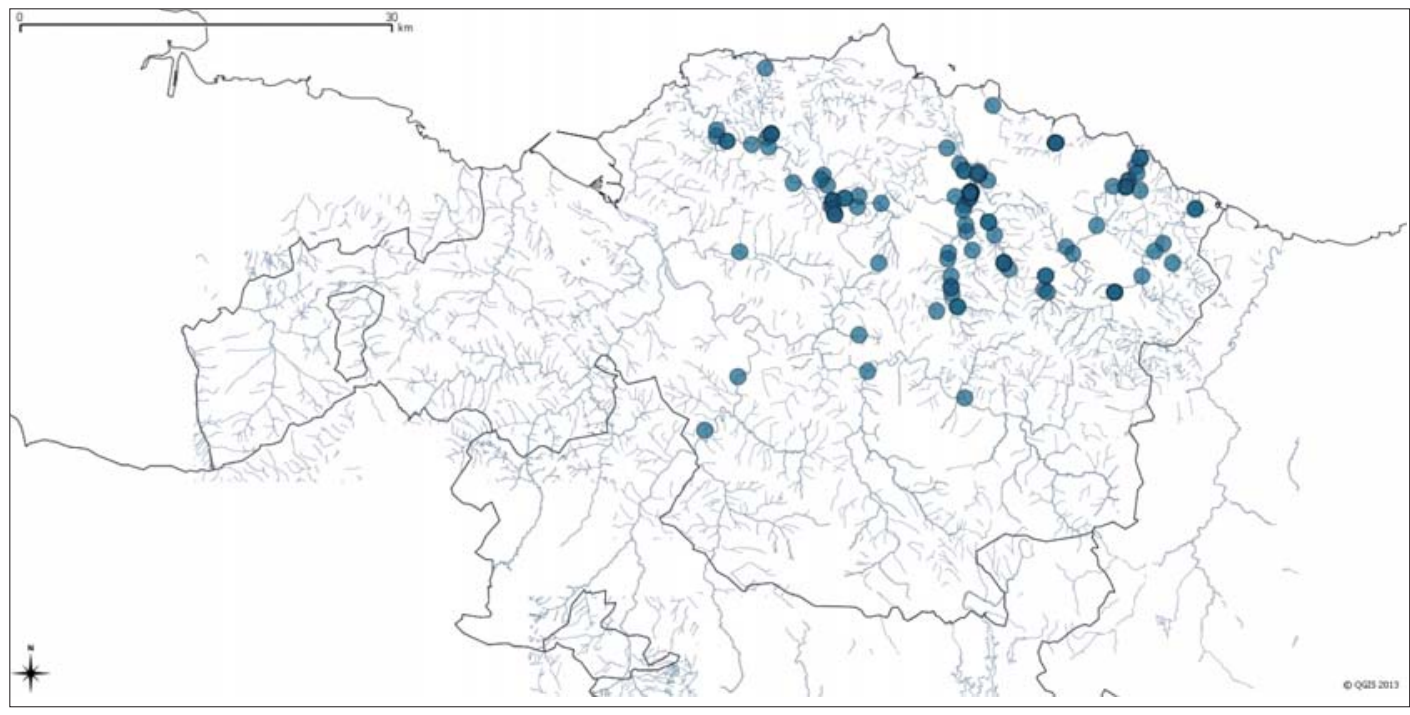

Fig. 4-5. - Capturas de visones americanos en el periodo 2011-2013, y nuevos datos de ejemplares atropellados y observaciones directas (Zuberogoitia \& Torres, 2013)

Fig. 4-5. - Records of trapped American mink and new data of road casualties and sights between 2011 and 2013 (Zuberogoitia \& Torres, 2013). 
sexos, de forma que las hembras tienden a ocupar preferentemente los tributarios menores, las vegas y las marismas, mientras que los machos alcanzan mayores densidades en las partes medias de los cauces principales (Fig. 5, Zuberogoitia \& Torres, 2013).

Dentro de las áreas de campeo de los visones existen áreas de uso intenso (áreas núcleo) donde se encuentra una alta disponibilidad de recursos (alimento, refugio y pareja) y otras áreas de baja intensidad de uso, utilizadas sólo de paso (Zabala \& Zuberogoitia, 2003d; Zabala et al., 2003, 2006, 2007c).

Teniendo en cuenta los datos de atropellos y observaciones directas no todos los visones presentan áreas de campeo lineales, sino que parece existir una población flotante de individuos juveniles y/o marginales en dispersión que son "empujados" por los machos dominantes fuera de las cauces principales e incluso fuera de los há- bitats acuáticos (Zuberogoitia \& Zabala, 2003b). Estos individuos marginales probablemente están en continuo movimiento buscando nuevos territorios a la espera de ocupar alguno que quede libre (Garin et al., 2002a).

\section{SELECCIÓN DEL HÁBITAT}

Mientras que la especie autóctona ocupa principalmente ríos y zonas pantanosas (Garin et al., 2002b; Garin et al., 2002a; Zabala \& Zuberogoitia, 2003a; Zabala et al., 2003; Zabala et al., 2006a), la especie invasora es mucho más versátil y ocupa de manera oportunista casi cualquier hábitat acuático, incluida la costa (Zabala et al., 2006a; 2007c; Zabala \& Zuberogoitia, 2007). Los visones europeos limitan sus áreas de campeo al entorno inmediato de los cauces fluviales, abarcando tanto la lámina de agua como el talud y los primeros metros de orilla, aunque también existen ejemplares divagantes y flotan-
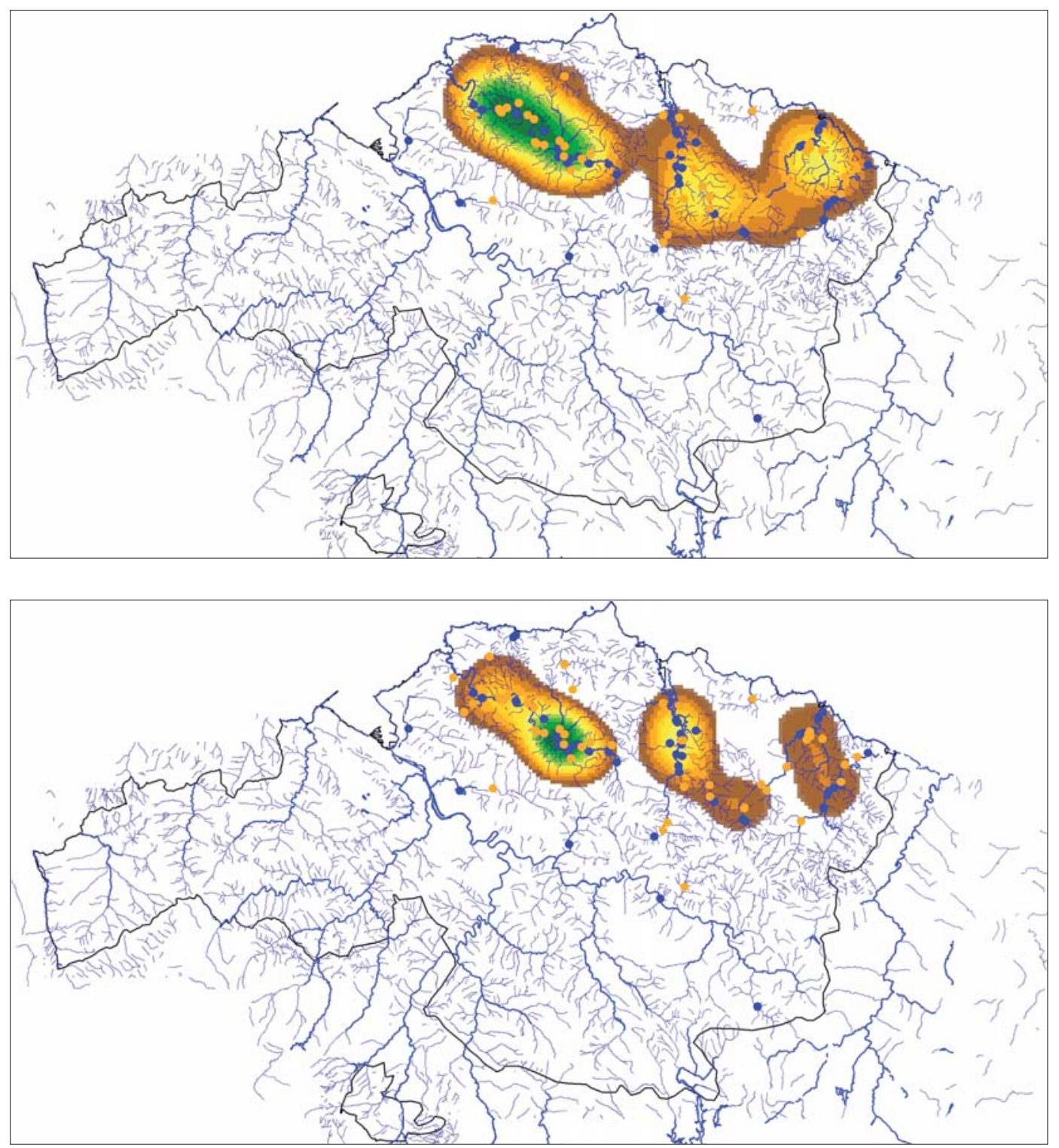

Fig. 5. - Areas kernel al $80 \%$ sobre la distribución de las capturas de visones americanos, hembras (Fig. 5a) y machos (Fig. 5b), a lo largo de los últimos seis años (2008-2013). Los puntos azules representan capturas de machos y los puntos naranjas son capturas de hembras. La abundancia de capturas esta relacionada con la intensidad de los colores, de forma que va de los marrones a los verdes, o lo que es lo mismo, de zonas de menor densidad de capturas a zonas de mayor densidad de capturas por sexos (Zuberogoitia \& Torres, 2013).

Fig. 5. - Kernel areas $(80 \%)$ calculated considering the distribution of trapped American mink, females (Fig. 5a) and males (Fig. 5b), between 2008 and 2013. Blue dots are males and orange dots are females. The abundance of trapping mink is related with the colour intensity, from brown (low density) to green (high density) (Zuberogoitia \& Torres, 2013). 
tes que pueden aprovechar puntualmente otros recursos terrestres (Zuberogoitia \& Zabala, 2003b). Los visones americanos también mantienen un uso elevado del entorno fluvial, aunque efectúan salidas fuera de los cauces hasta en un 10\% de las ocasiones, Ilegando a alejarse más de 100 m del río (Zabala, 2006; Zabala et al. 2007c). Tanto los machos como las hembras de ambas especies seleccionan riberas con alta disponibilidad de arbustos, tanto para descansar como durante los periodos de actividad. De hecho, los tramos de uso intenso se caracterizan, invariablemente, por la presencia de grandes zarzales. El tipo de especie vegetal no es el referente seleccionado, sino que es la estructura en maraña la que seleccionan, ya sean zarzas, espinos, carrizos, etc. (Zabala et al., 2003; Zabala \& Zuberogoitia, 2003d; Zuberogoitia et al., 2005a,b; Zabala, 2006). Las estructuras arbustivas densas y enmarañadas les proporcionan no sólo aislamiento térmico, sino también un refugio seguro donde cazar, consumir las presas y descansar, a salvo de depredadores (gatos, perros, zorros, rapaces, etc.).

En general ambas especies de visones utilizan un encame diferente cada día, salvo las hembras con crías. Los machos de visón europeo utilizan cada encame 1,3 veces ( $D E=1,0$; Garin et al., 2002b), los machos de visón americano 1,9 veces $(D E=1,5)$ y las hembras 1,6 veces (DE = 0,9; Zabala et al., 2006b). Los encames de los visones americanos suelen situarse en los taludes de los ríos a $9 \mathrm{~m}(\mathrm{DE}=15)$ en el caso de los machos y a $7 \mathrm{~m}$ (DE = 15) en el de las hembras, encontrándose en madrigueras bajo tierra el $30 \%$ de las veces y en edificios en $24,6 \%$ de los casos para las hembras y un $1,9 \%$ de los machos. La alta frecuencia de uso de cuadras, garajes y gallineros por parte de las hembras está relacionada con condiciones meteorológicas adversas (Zabala et al., 2007cb). Este comportamiento, además, deriva en un alto índice de afección a gallineros.

En cuanto a los factores que limitan la presencia de visones europeos, la contaminación y la canalización de los ríos son dos de los factores principales que explican la ausencia de la especie de ciertos ríos (Zabala et al., 2006a). La canalización de los cauces sustituye los taludes de tierra y la vegetación fluvial por paredes de hormigón o piedra donde los visones no encuentran refugios para evitar la depredación. Asimismo, las canalizaciones afectan a la disponibilidad de refugio y alimento de las presas (macroinvertebrados, peces, micromamíferos, anfibios y aves), reduciéndose la abundancia y diversidad de especies y, por tanto, los recursos tróficos disponibles para los visones.

Además, la fragmentación de los ríos (obras de drenaje, entubamientos, presas, etc.) condiciona la viabilidad de un cauce para acoger y mantener poblaciones de visones, tanto europeo como americano (Zuberogoitia et al., 2013). Los modelos muestran como los visones europeos dependen de tramos de ríos libres de barreras que fragmentan la conexión con los tributarios. Asimismo, los visones americanos se muestran más tolerantes a la fragmentación, aunque sucumben al efecto de las barreras ocasionadas por las obras de drenaje que dificultan el acceso entre el río y los arroyos.

\section{ACTIVIDAD}

Los visones europeos son básicamente nocturnos, con picos máximos de actividad a media noche durante el celo, mientras que fuera del periodo de celo no se dan diferencias notables de actividad a lo largo de la noche (Garin et al., 2002a). Por el contrario, los visones americanos se muestran activos tanto de día como de noche, sin ningún patrón claro, siendo el porcentaje de actividad diurno del 43,5\% (Zuberogoitia et al., 2006). Estas diferencias favorecen la explotación de recursos tróficos alternativos por parte de la especie invasora, pudiendo depredar sobre un amplio espectro trófico tanto de presas nocturnas como diurnas (estas últimas fuera del alcance del visón europeo). Por tanto, ello debería de conferir al visón americano una mayor eficiencia en el consumo de los recursos disponibles.

Durante los periodos de actividad, los machos de los visones europeos se distribuyen a lo largo de su territorio, pero durante los periodos de descanso se sitúan cerca de los bordes del mismo, lo que parece ser una forma energéticamente eficaz de controlar las posibles entradas de otros visones, así como hacer notar su presencia (Zabala \& Zuberogoitia, 2003c), especialmente en una zona tan Iluviosa como Bizkaia, donde las lluvias y los cauces torrenciales tienden a eliminar con mayor frecuencia cualquier marca dejada por estos (excremento, orina, huella, ...).

\section{AMENAZAS}

Las amenazas que afectan al visón europeo en Bizkaia son fundamentalmente de dos tipos: ambientales y de competencia con una especie exótica invasora.

Entre las principales primeras destacan la alteración del hábitat, la contaminación del agua y la canalización de los ríos, aunque también puede verse afectado por la desaparición de la cubierta arbustiva y arbórea de las riberas (Zabala et al., 2006a, 2007a). La creciente tendencia a la canalización y fragmentación de los ríos está llevando al aislamiento poblacional de la especie en el área de estudio, tanto a nivel de áreas de campeo como a nivel de potencial expansivo. Las zonas de río canalizadas con estructuras de hormigón y piedra, donde los taludes son verticales y no existe vegetación de ribera, son tramos de poca idoneidad de hábitat y de gran riesgo para cualquier visón que se ve indefenso y desprovisto de cualquier escondite o vía de escape en caso de verse amenazado, por lo que suelen evitar atravesarlos. Esas zonas canalizadas favorecen la pérdida de conexión entre áreas de campeo y la reducción de los tramos útiles de los ríos (Zuberogoitia et al., 2005b). Además, la mayoría de las grandes infraestructuras viarias existentes (carreteras, autovías, autopistas, ferrocarril, y el futuro Tren de Alta Velocidad) discurren paralelas a los ríos cortando perpendicularmente los tributarios mediante diversas estructuras 
como puentes, galerías, pasos y drenajes, de forma que el flujo de fauna se puede ver condicionado e, incluso, interrumpido dependiendo del tipo de estructura utilizada y la adecuación de los pasos de fauna (Zuberogoitia et al., 2013). Así pues, estas infraestructuras fragmentan los ríos aislando también los núcleos de visones, y podrían ser una de las causas que explicarían la ausencia de poblaciones estables de visones, tanto europeos como americanos, en los ríos Ibaizabal y Nervión (ambos fuertemente afectados por numerosas estructuras que fragmentan los tributarios y extensas superficies canalizadas), así como la paulatina desaparición de los visones europeos de tramos de río recientemente afectados por obras (Zuberogoitia et al., 2013). En lo relativo a la contaminación del agua, parece ser que en aquellos tramos en los que se incrementa la contaminación se reducen las probabilidades de encontrar poblaciones asentadas de visones europeos (Zabala et al., 2006a).

La competencia con el visón americano es el otro gran factor que amenaza al visón europeo en Bizkaia. Desde el establecimiento de la especie invasora en el medio natural hace casi dos décadas, la especie autóctona se ha visto enormemente afectada por la competencia interespecífica en un hábitat ya de por sí alterado, como acabamos de ver. Por ejemplo, en la Reserva de la Biosfera de Urdaibai se pasó de un índice de captura de un visón europeo cada 146,3 TN (trampas-noche) durante la temporada 1999/2000 (Rallo et al., 2001) en ausencia de visones americanos a un índice de uno cada 411 TN en 2009 y 742 TN en 2010, ambos periodos con presencia de la especie invasora; en estos dos últimos periodos los índices de captura para los visones americanos fueron de uno cada 94,8 TN y 106 TN respectivamente. Por lo tanto, parece que el establecimiento de nuevas poblaciones de visones americanos reduce y sustituye las poblaciones de visón europeo en poco tiempo, superando las densidades poblacionales de la especie autóctona en ausencia de la invasora. No obstante, incluso en el seno de las poblaciones de visones americanos establecidas hace dos décadas (como en la cuenca del río Butrón), aún subsisten algunos individuos de visón europeo fuera de los cauces principales, relegados a zonas subóptimas, en regatos y arroyos de menor calidad (ver Zuberogoitia et al., 2005b). Estos ejemplares parecen mostrar una tendencia a reocupar las áreas de campeo óptimas (cauce principal y tributarios principales) tras la eliminación de los visones americanos de esas zonas gracias a programas de control (Rodríguez-Refojos \& Zuberogoitia, 2010).

\section{CONCLUSIONES}

Actualmente el visón europeo ha desaparecido de gran parte de su área de distribución histórica en Bizkaia, y parece estar aproximándose al umbral de la extinción, en una situación crítica de conservación. La mejor situación podría darse en la zona oeste de la provincia (Kadagua), libre de visón americano (parece que la especie no es capaz de colonizar las cuencas intermedias) y en posible conexión con poblaciones de otras provincias. Re- cientemente se ha detectado la presencia estable de nutria, Lutra lutra (Linnaeus, 1758) (Rodríguez-Refojos \& Zuberogoitia, 2011; Otsoaren Taldea Zalla, com. pers.) que podría suponer otro factor de competencia más (Bonesi \& MacDonald, 2004). En los cauces del río Butrón, del Oka y del Artibai podrían perdurar aún pequeñas poblaciones en condiciones extremas.

Las causas del declive del visón europeo en Bizkaia parecen ser la fragmentación y la degradación del hábitat, así como la competencia interespecífica por el incremento de las poblaciones de visón americano. La ausencia de citas en zonas donde la especie estuvo presente puede explicarse mediante dos hipótesis no excluyentes: (1) Que hayan tenido lugar extinciones locales, a las cuales son más propensas las poblaciones pequeñas y fragmentadas. (2) Que la competencia interespecífica con el visón americano haya relegado a la especie autóctona a zonas vacantes de menor calidad. En este sentido, el control de la especie invasora debería beneficiar claramente al visón europeo al liberarlo de la presión que ejerce el visón americano.

\section{AGRADECIMIENTOS}

Los programas de estudio y de control/erradicación del visón americano han sido dirigidos y financiados por el Servicio de Conservación, Red Natura 2000 y Biodiversidad del Departamento de Agricultura primero (20042011), y el Dpto de Medio Ambiente, Patrimonio Natural y Biodiversidad después (2012-2013). Todo este trabajo no hubiera sido posible sin el esfuerzo de trampeo en el campo en el que ha participado un nutrido grupo de personas a las que queremos mostrar nuestro agradecimiento, especialmente a A. Azkona, C. Rodríguez-Refojos y a los agentes forestales del Servicio de Recursos Naturales, Fauna Cinegética y Pesca de la Diputación Foral de Bizkaia: A. Alava, J. Aguirre, U. Dañobeitia, E. Díaz, A. Egia, J.R. Egia, M. Eguizabal, G. Etxabe, A. Galarza, E. Garamendi, E. Goikolea, L. González, A. Goñi, A. Jaureguizar, K. Llaguno, F. Martínez, J.I. Martínez, A. Oregi, J.M. Pérez de Ana, J. Ruíz, D. Rodríguez, J.M. Sagarna, M. San Sebastián y J. Santiesteban. Gracias también al Centro de Recuperación de Fauna Silvestre de Bizkaia (CRFSB) y a todo su equipo. Jordi Ruiz-Olmo y un revisor anónimo aportaron valiosas sugerencias que sirvieron para mejorar el manuscrito original.

\section{BIBLIOGRAFÍA}

Aihartza, J., Zuberogoitia, I., Camacho, E. Torres, J.J. 1999. Status of carnivores in Biscay (N Iberian peninsula). Miscelanea Zoologica 22(1): 41-52.

Álvarez, J., Bea, A., Faus, J. M., Castién, E., Mendiola, I. 1985. Atlas de los vertebrados continentales de Álava, Vizcaya y Guipúzcoa. Gobierno Vasco. Bilbao.

Bonesi, L., Macdonald, D.W. 2004. Impact of released Eurasian otters on a population of 353 American mink: a test using an experimental approach. Oikos 106: 9-18 
Bravo C., Bueno F. 1999. Visón Americano, Mustela vison Schreber, 1977. Galemys 11: 3-16.

Camacho, E., Zuberogoitia, I. 1998. La Nutria en Bizkaia. En: La Nutria en España. J. Ruiz-Olmo, M. Delibes: 179-180. SECEM. Barcelona.

Fernandez de Mendiola, J.A., Bea, A. (Eds). 1998. Vertebrados Continentales: Situación actual en la comunidad auronoma del País Vasco. Gobierno Vasco. Vitoria-Gasteiz.

Garin, I., Aihartza, J., Zuberogoitia, I., Zabala, J. 2002a. Activity pattern of European mink (Mustela lutreola) in Southwestern Europe. Z. Jagdwiss. 48: 102-106.

Garin, I., Zuberogoitia, I., Zabala, J., Aihartza, J., Clevenger, A., Rallo, A. 2002b. Home range of European mink Mustela lutreola in southwestern Europe. Acta Theriologica 47(1): 55-62.

Maran, T., Macdonald, D.W., Kruuk, H., Sidorovich, V., Rozhnov, V.V. 1998. The continuing decline of the European mink Mustela lutreola: evidence for the intraguild aggression hypothesis. In: Behaviour and ecology of riparian mammals. Symposium of the Zoological Society of London 71. N. Dunston, M.L. Gorman: 297323. Cambridge University Press. Cambridge.

Michaux, J.R., Hardy, O.J., Justy, F., Fournier, F., Kranz, A., Cabria, M., Davison, A., Rosoux, R., Libois, R. 2005. Conservation genetics and population history of the threatened Europeanmink Mustela lutreola, with an emphasis on the west European population. Mol. Ecol. 14(8): 2373-2388. (doi: 10.1111/j.1365294X.2005.02597.x)

Palazón, S. 1998. Distribución, morfología y ecología del visón Europeo (Mustela lutreola Linnaeus, 1761) en la Península lbérica. Tesis Doctoral. Universitat de Barcelona. Barcelona.

Palazón, S., Ruiz-Olmo, J. 1997. El visón europeo (Mustela lutreola) y el visón americano (Mustela vison) en España. Ministerio de Medio Ambiente. Madrid.

Peltier, D., Lodé, T. 2003. Molecular survey of genetic diversity in the endangered European mink Mustela lutreola. C.R. Biologies 325: S49-S53.

Podra, M., Gómez, A., Palazón, S. 2013. Do American mink kill European mink? Cautionary message for future recovery efforts. European J. Wildl. Res. 59(3): 431-440. DOI 10.1007/s10344013-0689-8.

Rallo, A., Aihartza, J., Garin, I., Zabala, J., Zuberogoitia, I., Clevenger, A.P., Gómez, M. 2001. Inventario, distribución y uso del espacio de los mamíferos de la Reserva de la Biosfera de Urdaibai. Informe técnico. Proyecto PU-1998-8. Gobierno Vasco, Dpto. de Educación, Universidades e Investigación y Dpto. de Ordenación del Territorio y Medio Ambiente. Vitoria-Gasteiz.

Rodríguez de Ondarra, P.M. 1955. Hallazgo, en Guipúzcoa, de un mamífero no citado en la "Fauna Ibérica" de Cabrera: El "Putorius lutreola". Munibe 7(4): 201-207.

Rodríguez de Ondarra, P. 1963. Nuevos datos sobre el visón en España. Munibe 15: 103-110.

Rodríguez-Refojos, C., Zuberogoitia, I. 2010. Liberación competitiva del visón europeo (Mustela lutreola) en Bizkaia tras el control del visón americano (Neovison vison). En: Actas del 3er Congreso Nacional sobre Especies Exóticas Invasoras "EEl 2009". GEIB Grupo Especialista en Invasiones Biológicas (Ed.): 261-266. GEIB. León. (Serie Técnica; 4).

Rodríguez-Refojos, C., Zuberogoitia, I. 2011. Middle-sized carnivores in mosaic landscapes: the case of Biscay (SW Europe). En: Middle-sized carnivores in agricultural landscapes. L.M. Rosalino, C. Gheler-Costa (Eds.): 105-126. Nova Science Publishers. New York, USA.
Sidorovich, V.E., Polozov, A.G., Zalewski, A. 2010. Food niche variation of European and American mink during the American mink invasion in north-eastern Belarus. Biol. Invasions 12: 2207-2217. doi:10.1007/s10530-009-9631-0.

Wilson, D.E., Mittermeier, R.A. (Eds). 2009. Handbook of the Mammals of the World. Vol.1. Carnivores. Lynx. Barcelona.

Zabala, J., Zuberogoitia, I. 2003a. Current and historical distribution of European Mink Mustela lutreola in Biscay. Evolution and comments on the results. Small Carniv. Conserv. 28: 4-6.

Zabala, J., Zuberogoitia, I. 2003b. Is the European Mink Mustela lutreola a longstanding member of the Iberian fauna or a midtwentieth-century arrival? Small Carniv. Conserv. 28: 8-9.

Zabala, J., Zuberogoitia, I. 2003c. Implications of territoriality in the spatial ecology of European Mink (Mustela lutreola). Biota 4(1-2): 121-127.

Zabala, J., Zuberogoitia, I. 2003d. Habitat use of male European mink (Mustela lutreola) during the activity period in south western Europe. Z. Jagdwiss 49: 77-81.

Zabala, J. 2006. Distribution and spatial ecology of semi-aquatic mustelids (Carnivora: Mustelidea) in Biscay. PhD Thesis. Universidad del País Vasco. Leioa, Bilbao.

Zabala, J., Zuberogoitia, I., González-Oreja, J.A. 2010. Estimating costs and outcomes of invasive American mink (Neovison vison) management in continental areas: a framework for evidence based control and eradication. Biol. Invasions 12: 2999-3012.

Zabala, J., Zuberogoitia, I., Martínez, J.A. 2004. The Historical and current distribution of the Iberian population of European mink (Mustela lutreola). Lutra 47(2): 101-112

Zabala, J., Zuberogoitia, I., Martínez, J.A. 2006a. Factors affecting occupancy by the European mink in South-Western Europe: a predictive model for evaluating the incidente of biotic and abiotic factors as a tool for setting management and conservation guidelines. Mammalia 3: 193-201.

Zabala, J., Zuberogoitia, I. 2007a. Modelling the incidence of fragmentation at different scales in the European mink (Mustela lutreola) population and the expansion of the American mink (Mustela vison) in Biscay. Small Carniv. Conserv. 36: 14-17.

Zabala, J., Zuberogoitia, I., Martínez, J.A. 2007b. Spacing pattern, intrasexual competition and niche segregation in American Mink. Ann. Zoologici Fennici 44: 249-258.

Zabala, J., Zuberogoitia, I., Martínez, J.A. 2007c. Winter habitat preferences of feral American mink Mustela vison in Biscay, Northern Iberian Peninsula. Acta Theriologica 52(1): 27-36.

Zabala, J., Zuberogoitia, I., Garin, I., Aihartza, J. 2003. Landscape features in the habitat selection of European mink (Mustela lutreola) in south-western Europe. J. Zool. London 260: 1-7.

Zuberogoitia, I., Torres, J.J. 2013. Control-erradicación del visón americano (Neovison vison) en Bizkaia. Diputación Foral de Bizkaia, Dpto. de Medio Ambiente, Patrimonio Natural y Biodiversidad. Informe técnico inédito.

Zuberogoitia, I., Torres, J.J. 2012. El visón europeo (Mustela lutreola) en Bizkaia: Análisis de su situación y propuesta de medidas para detener su extinción. Diputación Foral de Bizkaia, Dpto. de Medio Ambiente, Patrimonio Natural y Biodiversidad. Informe técnico inédito.

Zuberogoitia, I. Zabala, J. 2003a. Aproximación a la distribución del Visón Americano en Bizkaia. Galemys 15 (1): 29-35.

Zuberogoitia, I., Zabala, J. 2003b. Does European Mink use only rivers or do they also use other habitats? Small Carniv. Conserv. 28: 7-8. 
Zuberogoitia, I., Campos, L.F., Torres, J.J. 1997. La situación de los mustélidos en Bizkaia. Sustrai 46: 45-47.

Zuberogoitia, I., Torres, J.J., Zabala, J., Campos, M.A. 2001. Carnívoros de Bizkaia. BBK. Bilbao. (Temas vizcaínos 315).

Zuberogoitia, I., Zabala, J., Torres, J.J. 2005a. Estudio de hábitat y poblaciones del visón europeo en Bizkaia. Informe Inédito. Diputación Foral de Bizkaia, Servicio de Conservación y Espacios Naturales Protegidos.

Zuberogoitia, I., Zabala, J., Torres, J.J. 2005b. Requerimientos ecológicos, uso del hábitat, interacciones inter-especificas y medidas de gestión del visón europeo y americano en Bizkaia. Informe Inédito. Diputación Foral de Bizkaia, Servicio de Conservación y Espacios Naturales Protegidos.
Zuberogoitia, I., Zabala, J., Martínez, J.A. 2006. Diurnal activity and observations of the hunting and ranging behaviour of the American mink (Mustela Vison). Mammalia 70(3-4): 310-312.

Zuberogoitia, I., González-Oreja, J.A., Zabala, J., Rodríguez-Refojos, C. 2010. Assesing the control/eradication of an invasive species, the American mink, based on field data; how much would it cost? Biodivers. Conserv. 19: 1455-1469.

Zuberogoitia, I., Zalewska, H., Zabala, J., Zalewski, A. 2013. The impact of river fragmentation on the population persistence of native and alien mink: an ecological trap for the endangered European mink. Biodivers. Conserv. 22: 169-186. 